\title{
Coating Methods for Surface Modification of Ammonium Nitrate: A Mini-Review
}

\author{
Baha I. Elzaki ${ }^{1,2}$ and Yue Jun Zhang ${ }^{1, *}$ \\ 1 School of Chemical Engineering, Nanjing University of Science and Technology, Nanjing 210094, Jiangsu, \\ China; bhaeldeen8888@yahoo.com \\ 2 Department of Chemical Engineering, College of Engineering, Karary University, Omdurman 12304, Sudan \\ * Correspondence: zhyuejun@njust.edu.cn; Tel.: +86-25-8431-5083
}

Academic Editor: Jiyoung Kim

Received: 20 April 2016; Accepted: 15 June 2016; Published: 23 June 2016

\begin{abstract}
Using ammonium nitrate (AN) as a propellant oxidizer is limited due to its hygroscopicity. This review consolidated the available information of various issues pertaining to the coating methods of the surface modification of ammonium nitrate for reducing its hygroscopicity. Moreover this review summarizes the recent advances and issues involved in ammonium nitrate surface modification by physical, chemical and encapsulation coating methods to reduce the hygroscopicity. Furthermore, coating materials, process conditions, and the hygroscopicity test conditions are extensively discussed along, with summaries of the advantages and disadvantages of each coating method. Our findings indicated that the investigation and development of anti-hygroscopicity of $\mathrm{AN}$, and the mechanisms of surface modification by coating urgently require further research in order to further reduce the hygroscopicity. Therefore, this review is useful to researchers concerned with the improvement of ammonium salts' anti-hygroscopicity.
\end{abstract}

Keywords: ammonium nitrate; chemical coating; encapsulation coating; hygroscopicity; modification surface; physical coating

\section{Introduction}

Ammonium nitrate (AN) $\mathrm{NH}_{4} \mathrm{NO}_{3}$ is an inorganic salt (Figure 1). It is low cost, safe and has a simple manufacturing process $[1,2]$.

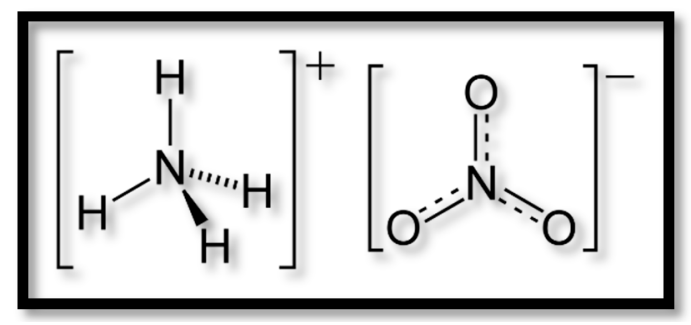

Figure 1. Formula of ammonium nitrate.

Pure AN is a colorless salt with relative density equal to $1.725 \mathrm{~g} / \mathrm{cm}^{3}$ and a melting point of $169{ }^{\circ} \mathrm{C}$. The decomposition process is significantly promoted at a slightly higher temperature of $210^{\circ} \mathrm{C}$ [3-5]. AN is widely used in fertilizers, and as an active component in explosive mixtures. It is a strong oxidizer and an insensitive explosive $[4,6,7]$. AN has a positive oxygen balance, and the nitrate ion acts as the source of oxygen, resulting in a promising compound as a propellant and gas generator [8-10]. The phase transition in pure AN can also occur at different temperatures as demonstrated in Figure 2 [11,12]. 


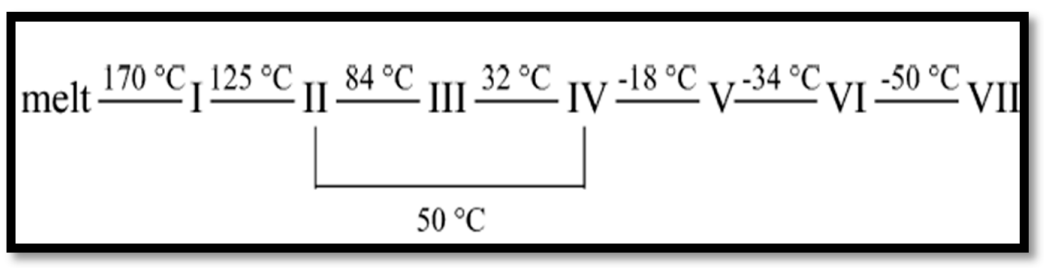

Figure 2. Phase transitions of AN.

Recently, there has been renewed interest in a clean-burning propellant, aiming at green propellants with $\mathrm{HCl}$-free burning. Ammonium perchlorate (AP) was replaced by different oxidizers because it releases toxic gases. There are ammonium dinitramide (ADN) and hydrazinium nitroformate (HNF) energetic oxidizers, but these are not available in adequate quantities [13-16]. AN-based composite propellants are primarily attractive due to the combustion products without toxic gases (HCl-free) [17]. Although ammonium nitrate is suitable as an oxidizer in large rocket motors, it is, however, restricted due to the hygroscopicity $[18,19]$. Furthermore, the surfaces of the AN solid particles are strongly polar, which cause hygroscopicity [20,21]. Hygroscopicity of AN has been pinpointed as the major cause for caking, and has become the biggest obstacle for its usage explosives and propellants [22,23]. Generally, reducing the hygroscopicity of AN has been studied by many researchers using surface modification techniques, by coating AN particles with different types of coating methods, in particular physical, chemical and encapsulation coating methods. To the best of our knowledge, the available coating methods that modify the surface of AN have not been aggregated and thoroughly reviewed. Therefore, the objective of this paper is to review the recent studies for the surface modification of AN to reduce the hygroscopicity, with an attempt to summarize the relevant information with emphasis on the main coating methods such as physical coating, chemical coating, and encapsulation coating methods. This consequently increases the effectiveness of the use of AN as a solid propellant oxidizer. The above-mentioned methods and concerns have been deeply discussed and compared to each other. The recent advances and development in this regard have been thoroughly addressed.

\section{Coating Methods}

Surface modification of AN with several coating methods was applied in order to reduce hygroscopicity, which has been tackled by several previous studies. This section will discuss these methods as follows:

\subsection{Physical Coating Method}

The physical coating method is used to modify the surface of AN particles to reduce the hygroscopicity. In this method the interaction between the surface of AN particles and the coating agents occurs by physical absorption; for example, the polar head of the surfactant has an affinity to the polar surface of AN particles and makes a hydrophobic uniform membrane on the surface with the hydrophobic tails of the surfactant materials [24]. In addition, the success of this process mainly depends on the solubility (the solubility of the surfactant is controlled by the temperature) of the surfactant and the insolubility of $\mathrm{AN}$, as well as on the suspension of particles in aqueous solution, because the soluble surfactant can easily deposit on insoluble particles of AN, with the suspension making a uniform coating layer on the surface of the particles [25]. Moreover, the stirring and densities of solvents have significant roles in making the suspension system [26]. In fact, the mechanism of coating by surfactant materials probably varies from surfactant group to surfactant group and even within the same surfactant groups due to the different lengths of the tails [27]. In 1996, Chattopadhyay used stearic acid to coat the surface of the AN particles, and hydrophobic film was formed to achieve the purpose of preventing moisture. This study provided a worthy explanation on coating AN with stearic acid; however, no details were mentioned about the coating process and the hygroscopic test 
conditions [28]. Furthermore, there was a water-resistant base of an AN explosive composition made by blending the particles of AN with different groups, such as alkaline earth metals and earth metal salts of aliphatic carboxylic acids [29]. AN particles were modified by a composite consisting of anion, cationic, non-ion, and amphoteric surfactants. Therefore, the dispersion improved by adding a quantity of a dispersant agent such as diatomate or vermiculite; in addition the anti-water mechanism is shown in Figure 3. To our knowledge this is the first study on the coating of AN with a composite surfactant, which can be used as the base for the surface modification of AN with composite surfactant [30].

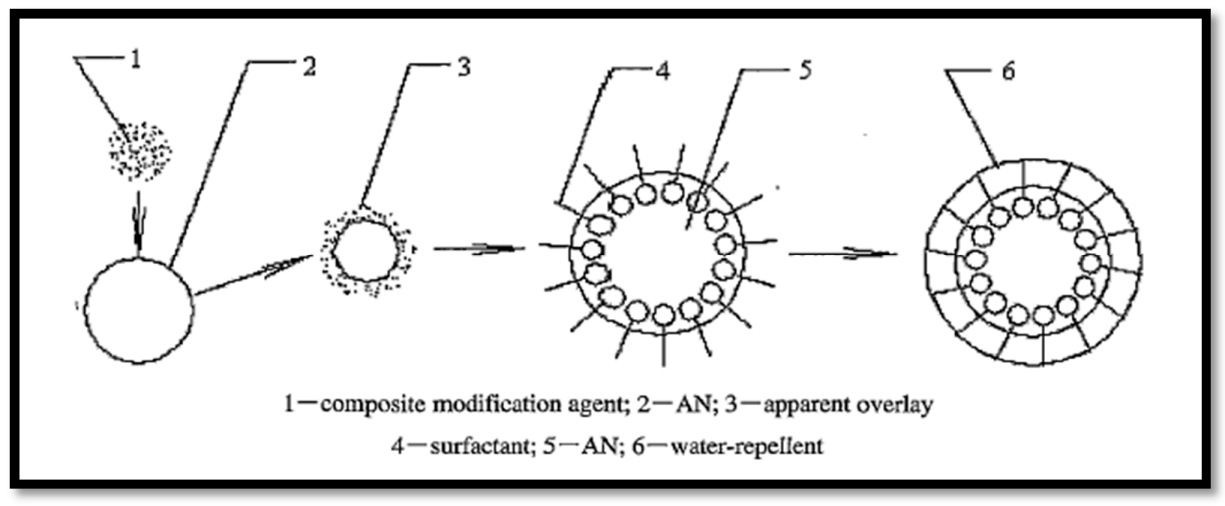

Figure 3. Micro-structure of composite-modified water-resistant powdery AN.

Another piece of research showed that the AN particles were coated with mineral oil. Under a temperature of $20^{\circ} \mathrm{C}, 65 \%$ relative humidity, and the absorption moisture time of $96 \mathrm{~h}$, the decline of the moisture absorption rate increased to $65 \%$ with the mass ratio of the coating layer at $1 \%$. It is worth mentioning that this study was classified as the highest level in the literature for the current rate of decline in the physical coating for a decrease in moisture [31]. Furthermore, Kun-lun Hu et al. used stearic acid, resin, wax, etc., as coating materials; the particle sizes of AN were 20-40 mesh in the melting process. Under the conditions of a temperature at $25^{\circ} \mathrm{C}$, a relative humidity of $90 \%$, and an absorption moisture time of $8 \mathrm{~h}$, the mass ratio of the coating layer was decreased from $6.25 \%$ to $2.17 \%$, and the decline was $65.28 \%$. This study used a short duration of the absorption moisture test with a high mass ratio of the coating layer [32]. Moreover, the coupling cationic surfactant ( $N, N$-Dimethyldodecylamine) has been used to improve the anti-hygroscopicity, anti-caking and explosion performance of AN particles [33]. For reducing hygroscopicity the heating melt method with different amounts of paraffin was used, resulting in a modification of AN particles [34]. Octadecylamine was also used to modify ammonium nitrate and characterized the contact angle to investigate the explosive performance [35]. The mechanism of interaction between ammonium nitrate and octadecylamine was studied by using SEM, XRD, XPS and IR, which resulted in the coating of the ammonium nitrate surface with octadecylamine through physical absorption, which improved the explosion performance [36]. The performances of modified AN using physical coating methods are summarized in Table 1.

Table 1. Performance of coated AN using the physical coating method.

\begin{tabular}{ccccccc}
\hline No. & Year & $\begin{array}{c}\text { Absorption } \\
\text { Moisture Rate (\%) }\end{array}$ & $\begin{array}{c}\text { Mass Ratio of } \\
\text { Coating Layer (\%) }\end{array}$ & $\begin{array}{c}\text { Absorption Moisture } \\
\text { Test Condition }\end{array}$ & $\begin{array}{c}\text { Decline of Absorption } \\
\text { Moisture (\%) }\end{array}$ & $\begin{array}{c}\text { Ref. } \\
\text { Mons }\end{array}$ \\
\hline 1 & 2003 & $1.62 \%$ & $4 \%$ & $\mathrm{~T}=20^{\circ} \mathrm{C}, \mathrm{RH}=83 \%, \mathrm{t}=48 \mathrm{~h}$ & $64.78 \%$ & {$[30]$} \\
2 & 2004 & $7 \%$ & $1 \%$ & $\mathrm{~T}=20^{\circ} \mathrm{C}, \mathrm{RH}=65 \%, \mathrm{t}=96 \mathrm{~h}$ & {$[0 \%$} & $65.28 \%$ \\
3 & 2006 & $2.174 \%$ & $2.17 \%$ & $\mathrm{~T}=25^{\circ} \mathrm{C}, \mathrm{RH}=90 \%, \mathrm{t}=8 \mathrm{~h}$ & {$[31]$} \\
4 & 2007 & $5.27 \%$ & - & $\mathrm{T}=25^{\circ} \mathrm{C}, \mathrm{RH}=90 \%, \mathrm{t}=30 \mathrm{~h}$ & $69.02 \%$ & {$[33]$} \\
5 & 2013 & $3.04 \%$ & $2.5 \%$ & $\mathrm{~T}=30^{\circ} \mathrm{C}, \mathrm{RH}=90 \%, \mathrm{t}=24 \mathrm{~h}$ & $88 \%$ & {$[34]$} \\
\hline
\end{tabular}




\subsection{Chemical Coating Method}

The chemical coating is a method used for AN particle modification to reduce hygroscopicity. In this method the adsorption of coating materials on the surface of the AN particles causes a chemical reaction resulting in the formation of a coating layer on the particles. AN particles with a size of 60-80 mesh were coated by silane coupling agents KH550 and KM602; the hygroscopicity test conditions were a temperature of $35^{\circ} \mathrm{C}$, a relative humidity of $92 \%$, and a time of $24 \mathrm{~h}$, and the decline of absorbed moisture was $38.7 \%$ in the AN modified with KH550. However, the mass ratio of the coating layer was not determined [37]. In contrast the decline of the moisture absorption increased to $56.25 \%$ when the AN particles were coated with an anionic surfactant mixture of lignosulfonate and urea, at a temperature of $35^{\circ} \mathrm{C}$, a relative humidity of $55 \%$, and a moisture absorption time of $24 \mathrm{~h}$. However, the mass ratio of the coating layer was not mentioned, nor was the relative humidity near the AN critical relative humidity [38]. Another piece of research showed the modification of AN particles sized 50-75 mesh with silane coupling agent KH792 as the coating material. The hygroscopicity was tested under conditions of a temperature of $20^{\circ} \mathrm{C}$, a relative humidity of $88 \%$, and a moisture absorption time of $8 \mathrm{~h}$, and the absorption rate of the moisture was decreased from $12.86 \%$ to $10.92 \%$, with a decline of $15.08 \%$. In this study, the mass ratio of the coating layer was not determined, and the decline of the moisture absorption was low [39]. Table 2 shows the performance of modified AN using a chemical coating method.

Table 2. Performance of coated AN using the chemical coating method.

\begin{tabular}{ccccccc}
\hline No. & Year & $\begin{array}{c}\text { Absorption } \\
\text { Moisture Rate }\end{array}$ & $\begin{array}{c}\text { Mass Ratio of } \\
\text { Coating Layer }\end{array}$ & $\begin{array}{c}\text { Absorption Moisture } \\
\text { Test Condition }\end{array}$ & $\begin{array}{c}\text { Decline of } \\
\text { Absorption Moisture }\end{array}$ & \begin{tabular}{c} 
Ref. \\
\hline 1
\end{tabular} \\
2 & 2003 & $11.4 \%$ & - & $\mathrm{T}=35^{\circ} \mathrm{C}, \mathrm{RH}=92 \%, \mathrm{t}=24 \mathrm{~h}$ & $38.7 \%$ & {$[37]$} \\
3 & 2005 & $0.21 \%$ & $0.3 \%$ & $\mathrm{~T}=35^{\circ} \mathrm{C}, \mathrm{RH}=55 \%, \mathrm{t}=24 \mathrm{~h}$ & $56.25 \%$ & {$[38]$} \\
\hline
\end{tabular}

\subsection{Encapsulation Methods}

Encapsulation is a new coating method. The capsule-like coating layer is formed on the surface of AN particles, which are homogeneous and of a certain thickness. The mechanism of encapsulation is shown in Figure 4. The process of encapsulation coating involves dispersing the AN particles in a solution of an encapsulating material dissolved in an organic solvent, suspending the whole system, and then evaporating away the organic solvent $[40,41]$. Based on the reported literature, the materials forming capsules are divided into three categories:

(1) Cellulose derivatives, such as nitrocellulose, ethyl cellulose.

(2) Resin and plastics, such as poly methyl methacrylate, acrylic acid resin, polyvinyl acetylate, polystyrene, etc.

(3) Elastomeric polymer such as polyurethane elastomer.

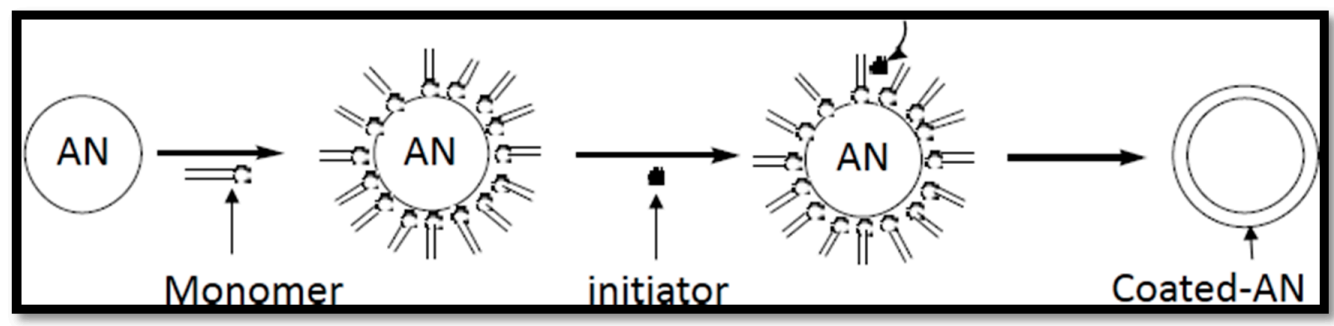

Figure 4. Monomer and polymeric particles adsorbed surface-coating schematic.

Depending on the different processes and approaches of the encapsulation coating process, there are three major categories: 
(1) Mechanical and physical methods such as the spray-drying method.

(2) Physical methods such as the phase separation method.

(3) Chemical methods such as the precipitation polymerization method.

Many studies were done to deal with the anti-moisture of ammonium nitrate. The study showed the modification of AN particles by the polymerization action in the interface of xylene/AN; the odctadecylamine forms a monolayer with self-assembling through hydrogen bonding on the surface of AN particles [42]. Meanwhile, the structure of the self-assembled monolayer film on the surface modified with octadecylamine and dimethyl benzene was characterized. This study has an explanation of the interaction between the monolayer and the AN [43]. The microencapsulation technology has been used for reducing the hygroscopicity and agglomeration of AN by coating it with polystyrene (PS) [44]. The AN particles were modified to improve the hygroscopicity and caking by coating particles using encapsulation through a physico-chemical process technique [45]. In addition, the AN particles were modified by liquid phase separation techniques using polyvinyl butyral (PVB), in order to reduce the hygroscopicity and caking capability [46]. The AN particles were modified by liquid phase separation technology, using polyvinyl acetate (PVAC), polyacrylamide (PAM), and polyethylene glycol (PEG) as coating materials. In this study, the modification effects of PVAC and PAM in the AN decreased the hygroscopicity and the coated particles, which have a better spherical shape [47]. Moreover, Yue (2003) used 10\% methyl methacrylate monomer as a coating material and $0.7 \%$ azobisisobutyeonitrile as an initiator in the reaction medium of petroleum ether, cyclohexane and toluene, with a reaction time of $8 \mathrm{~h}$ at $60^{\circ} \mathrm{C}$. Under the conditions, at temperature of $32{ }^{\circ} \mathrm{C}$, a relative humidity of $90 \%$ and an absorption moisture time of $24 \mathrm{~h}$, the absorption rate of moisture was decreased from $12.80 \%$ to $9.91 \%$, and the decline was $22.50 \%$. The absorption moisture test conditions were good, but the mass ratio of the coating layer and the AN particle sizes were not determined [37]. The surface polarity of AN was decreased by using a spray-drying technique, and a surfactant, a coupling agent and polyvinyl butyral as coating materials. In this study, the duration of the hygroscopicity test was short [48]. Furthermore, AN was coated with $4 \%$ polystyrene monomer, and $1 \%$ azobisisobutyeonitrile as an initiator was used in the polymerization reaction medium chloroform. Under the conditions of a temperature of $20^{\circ} \mathrm{C}$, a relative humidity of $75 \%$, and an absorption moisture time of $12 \mathrm{~h}$, the mass ratio of the coating layer was decreased from $1.24 \%$ to $0.623 \%$, and the decline was $88.8 \%$. The reported hygroscopicity was also affected by the particle size of the uncoated AN [49]. In 2013, Zhicheng et al. used methyl methacrylate as a monomer in precipitation polymerization, and azobisisobutyeonitrile as an initiator, and chloroform as a solvent, and the reaction time was $8 \mathrm{~h}$ at $65^{\circ} \mathrm{C}$. Under the conditions of a temperature of $35{ }^{\circ} \mathrm{C}$, a relative humidity of $92 \%$, and an absorption moisture time of $24 \mathrm{~h}$, the absorption rate of the moisture was decreased from $12.26 \%$ to $8.78 \%$, the decline was $28.35 \%$, and the mass ratio of the coating layer was 0.48 , which is the highest level in literature reported until now. In this study, the absorption moisture test conditions were high [50]. The performance of modified AN using encapsulation coating is summarized in Table 3. Although the surface modification of AN using physical coating, chemical coating and encapsulation coating methods had advantages in reducing the hygroscopicity, these methods also had disadvantages as shown in Table 4.

Table 3. Performance of coated AN using the encapsulation coating method.

\begin{tabular}{ccccccc}
\hline No. & Year & $\begin{array}{c}\text { Absorption } \\
\text { Moisture Rate }\end{array}$ & $\begin{array}{c}\text { Mass Ratio of } \\
\text { Coating Layer }\end{array}$ & $\begin{array}{c}\text { Absorption Moisture } \\
\text { Test Condition }\end{array}$ & $\begin{array}{c}\text { Decline of } \\
\text { Absorption Moisture }\end{array}$ & \begin{tabular}{c} 
Ref. \\
\hline 1
\end{tabular} \\
2 & 2003 & $9.91 \%$ & - & $\mathrm{T}=32{ }^{\circ} \mathrm{C}, \mathrm{RH}=90 \%, \mathrm{t}=24 \mathrm{~h}$ & $22.50 \%$ & {$[37]$} \\
2 & 2004 & $2.8427 \%$ & $1.5 \%$ & $\mathrm{~T}=30^{\circ} \mathrm{C}, \mathrm{RH}=94 \%, \mathrm{t}=8 \mathrm{~h}$ & $49 \%$ & {$[48]$} \\
3 & 2008 & $0.623 \%$ & - & $\mathrm{T}=20^{\circ} \mathrm{C}, \mathrm{RH}=75 \%, \mathrm{t}=12 \mathrm{~h}$ & $88 \%$ & {$[49]$} \\
4 & 2011 & $0.33 \%$ & - & $\mathrm{T}=30^{\circ} \mathrm{C}, \mathrm{RH}=75 \%, \mathrm{t}=24 \mathrm{~h}$ & $30.6 \%$ & {$[47]$} \\
5 & 2013 & $8.78 \%$ & $0.48 \%$ & $\mathrm{~T}=35^{\circ} \mathrm{C}, \mathrm{RH}=92 \%, \mathrm{t}=24 \mathrm{~h}$ & $28.35 \%$ & {$[50]$} \\
\hline
\end{tabular}


Table 4. Advantages and disadvantages of coating methods.

\begin{tabular}{|c|c|c|c|c|}
\hline Method & & Advantages & & Disadvantages \\
\hline Physical coating & $\begin{array}{l}(1) \\
(2) \\
(3) \\
(4) \\
(5)\end{array}$ & $\begin{array}{l}\text { Simple. } \\
\text { Convenient and easy to manufacture. } \\
\text { Improves the stability of the particles. } \\
\text { Safety. } \\
\text { Enhances the compatibility of particles with } \\
\text { other materials. }\end{array}$ & $\begin{array}{l}(1) \\
(2) \\
(3)\end{array}$ & $\begin{array}{l}\text { Uses a large amount of coating agent. } \\
\text { Thickness of coating layer not easy to control. } \\
\text { Large difference of interfacial tension } \\
\text { between the surface coating layer and the } \\
\text { polarity of AN. }\end{array}$ \\
\hline Chemical coating & $\begin{array}{l}(1) \\
(2) \\
(3)\end{array}$ & $\begin{array}{l}\text { Small dosage of coating agent. } \\
\text { Strong binding force. } \\
\text { The hydrophobic group made the thin layer } \\
\text { on the surface prevent hygroscopicity. }\end{array}$ & $\begin{array}{l}(1) \\
(2) \\
(3)\end{array}$ & $\begin{array}{l}\text { The surfactant and coupling agent have low } \\
\text { molecular weight. } \\
\text { The surfactant has a small solubility in water. } \\
\text { Low hygroscopicity properties. }\end{array}$ \\
\hline Encapsulation coating & $\begin{array}{l}(1) \\
(2) \\
(3) \\
(4)\end{array}$ & $\begin{array}{l}\text { Improves the physical properties of coated } \\
\text { particles on the surface. } \\
\text { Protects the particles from external moisture. } \\
\text { Polymer hygroscopicity was zero. } \\
\text { Coating layer is thin. }\end{array}$ & $\begin{array}{l}(1) \\
(2) \\
(3)\end{array}$ & $\begin{array}{l}\text { The brittle polymer is susceptible to cracking } \\
\text { during the drying process. } \\
\text { There are sticky polymer adhesives } \\
\text { not dispersed. } \\
\text { Polymer polarity low is difficult to stick on } \\
\text { surface of AN particles. }\end{array}$ \\
\hline
\end{tabular}

\section{Conclusions}

The hygroscopicity of AN has restricted its application in explosives and propellants. This mini-review clearly summarized the surface modification of AN particles using physical, chemical and encapsulation coating methods to reasonably reduce the hygroscopicity. Our findings indicated that further exploration and improvement of the anti-hygroscopicity of $\mathrm{AN}$ and the mechanisms of surface modifications are urgently required for a greater reduction in hygroscopicity.

Conflicts of Interest: The authors declare no conflict of interest.

\section{References}

1. Singh, G.; Felix, S. Evaluation of transition metal salts of NTO as burning rate modifier for HRPB-AN composite solid propellants. Combust. Flame 2003, 132, 422-432. [CrossRef]

2. Kim, J.-K.; Choi, S.-I.; Kim, E.J.; Kim, J.H.; Koo, K.-K. Preparation of Spherical Ammonium Nitrate Particles by Melt Spray. Ind. Eng. Chem. Res. 2010, 49, 12632-12637. [CrossRef]

3. Oommen, C.; Jain, S. Ammonium nitrate: A promising rocket propellant oxidizer. J. Hazard. Mater. 1999, 67, 253-281. [CrossRef]

4. Heller, A.N.; Cuffe, S.T.; Goodwin, D.R. Inorganic chemical industry. In Sources of Air Pollution and Their Control: Air Pollution; Academic Press: Cambridge, MA, USA, 2015; p. 191.

5. Marlair, G.; Kordek, M.-A. Safety and security issues relating to low capacity storage of AN-based fertilizers. J. Hazard. Mater. 2005, 123, 13-28. [CrossRef] [PubMed]

6. Mellor, J.W. A Comprehensive Treatise on Inorganic and Theoretical Chemistry; Longmans, Green: London, UK, 1922; Volume 2.

7. Oxley, J.C.; Smith, J.L.; Rogers, E.; Yu, M. Ammonium nitrate: Thermal stability and explosivity modifiers. Thermochim. Acta 2002, 384, 23-45. [CrossRef]

8. Kajiyama, K.; Izato, Y.-I.; Miyake, A. Thermal characteristics of ammonium nitrate, carbon, and copper (II) oxide mixtures. J. Therm. Anal. Calorim. 2013, 113, 1475-1480. [CrossRef]

9. Clay, R.B. Water-in-Oil Blasting Composition. U.S. Patent 4,111,727, 5 September 1978.

10. Vargeese, A.A.; Muralidharan, K.; Krishnamurthy, V. Thermal stability of habit modified ammonium nitrate: Insights from isoconversional kinetic analysis. Thermochim. Acta 2011, 524, 165-169. [CrossRef]

11. Kwok, Q.S.; Kruus, P.; Jones, D.E. Wettability of ammonium nitrate prills. J. Energetic Mater. 2004, 22, 127-150. [CrossRef]

12. Davey, R.; Ruddick, A.J.; Guy, P.D.; Mitchell, B.; Maginn, S.J.; Polywka, L.A. The IV-III polymorphic phase transition in ammonium nitrate: A unique example of solvent mediation. J. Phys. D Appl. Phys. 1991, 24, 176. [CrossRef] 
13. Borman, S. Advanced energetic materials emerge for military and space applications. Chem. Eng. News 1994, 72, 18-22. [CrossRef]

14. Matsunaga, H.; Habu, H.; Miyake, A. Thermal decomposition of the high-performance oxidizer ammonium dinitramide under pressure. J. Therm. Anal. Calorim. 2014, 116, 1227-1232. [CrossRef]

15. Heintz, T.; Pontius, H.; Aniol, J.; Birke, C.; Leisinger, K.; Reinhard, W. Ammonium Dinitramide (ADN)-Prilling, Coating, and Characterization. Propellants Explos. Pyrotech. 2009, 34, 231-238. [CrossRef]

16. Cui, J.; Han, J.; Wang, J.; Huang, R. Study on the crystal structure and hygroscopicity of ammonium dinitramide. J. Chem. Eng. Data 2010, 55, 3229-3234. [CrossRef]

17. Mathew, S.; Krishnan, K.; Ninan, K. Effect of energetic materials on thermal decomposition of phase-stabilised ammonium nitrate-An eco-friendly oxidiser. Def. Sci. J. 1999, 49, 65-69. [CrossRef]

18. Chaturvedi, S.; Dave, P.N. Review on thermal decomposition of ammonium nitrate. J. Energetic Mater. 2013, 31, 1-26. [CrossRef]

19. Gunawan, R.; Freij, S.; Zhang, D.K.; Beach, F.; Littlefair, M. A mechanistic study into the reactions of ammonium nitrate with pyrite. Chem. Eng. Sci. 2006, 61, 5781-5790. [CrossRef]

20. Komunjer, L.; Affolter, C. Absorption-evaporation kinetics of water vapour on highly hygroscopic powder: Case of ammonium nitrate. Powder Technol. 2005, 157, 67-71. [CrossRef]

21. Harris, J. Hygroscopicity of Ammonium Nitrate Samples; DTIC Document: Fort Belvoir, VA, USA, 1970.

22. Sinditskii, V.P.; Egorshev, V.Y.; Levshenkov, A.I.; Serushkin, V.V. Ammonium nitrate: Combustion mechanism and the role of additives. Propellants Explos. Pyrotech. 2005, 30, 269-280. [CrossRef]

23. Komunjer, L.; Pezron, I. A new experimental method for determination of solubility and hyper-solubility of hygroscopic solid. Powder Technol. 2009, 190, 75-78. [CrossRef]

24. Ye, Z.-W. Research on Improvement in Hydroscopicity of Ammonium Nitrate with Surfactants. Fine Chem. Dalian 2001, 18, 70-71.

25. Rosen, M.J.; Kunjappu, J.T. Surfactants and Interfacial Phenomena; John Wiley \& Sons: Hoboken, NJ, USA, 2012.

26. Myers, D. Surfactant Science and Technology; John Wiley \& Sons: Hoboken, NJ, USA, 2005.

27. Chen, T.; Lv, C. Study on Reducing AN Absorptivity with Surface Active Agents and Additives. Chin. J. Explos. Propellants 1998, 4, 19-21.

28. Chattopadhyay, A.K. Coating for Ammonium Nitrate Prills. U.S. Patent 5,567,910, 22 October 1996.

29. Patrick, F.D.; Rapstein, K.T.; Schrieber, C.F.; Wilson, J.S. Coated Explosive Comprising Ammonium Nitrate. U.S. Patent 3,287,189, 22 November 1966.

30. Huang, W.Y.; Yan, S.L.; Xie, X.H.; Guo, Z. The production and Implication of Composite Modified Water-Resistant Powdery Ammonium Nitrate. In Proceedings of the International Conference on Theory and Practice of Energetic Materials (IASPEP 2003), Guilin, China, 15-18 Octomber 2003; pp. 68-73.

31. Damse, R. Waterproofing materials for ammonium nitrate. Def. Sci. J. 2004, 54, 483-492. [CrossRef]

32. Hu, K.L.; Luo, N.; Huang, W.Y.; Ma, X.M.; Xu, X.F. Test and Study on the Modification of Ammonium N itrate by Coating Its Surface. Explos. Mater. 2006, 35, 14-17.

33. Ye, W. Research on properties of ammonium nitrate modified by coupling cationic surfactant. Inorg. Chem. Ind. 2007, 39, 26.

34. Xiong, Y.-T.; Liu, Z.-L. Improvement of the Hygroscopicity of AN by Modified Paraffin. Chin. J. Explos. Propellants 2013, 4, 50-53.

35. Lu, L.Y.; Yang, L.; Zhou, Y.K. Study on Contact Angle for Characterizing the Modifying Effect of Powder Ammonium Nitrate. Coal Mine Blasting 2009, 4, 4-6.

36. Lu, L.-Y.; Yang, L. Study on the Interaction Mechanism of Modified Ammonium Nitrate by O tadecylamine. Initiat. Pyrotech. 2010, 2, 41-43.

37. Wen, Y. Study on The Technics of Surface Modification of Ammonium Nitrate. Master's Thesis, Hunan University, Changsha, China, 2003.

38. Malash, G.; Hashem, H. Improving the properties of ammonium nitrate fertilizer using additives. Alex. Eng. J. 2005, 44, 685-693.

39. Zhang, X.D.; Li, J.M.; Yang, R.J.; Zhao, X.Q. Surface Modification of Phase Stabilized Ammonium Nitrate and Its Application in Solid Composite Propellants. Chin. J. Explos. Propellants 2009, 32, 5-9.

40. Masao, K.; Asaji, K.; Noriynki, M.; Tsutomu, Y. Encapsulation Method. U.S. Patent 3,691,090, 23 Octomber 2014. 
41. Umer, H.; Nigam, H.; Tamboli, A.M.; Nainar, M.S.M. Microencapsulation: Process, techniques and applications. Int. J. Res. Pharm. Biomed. Sci. 2011, 2, 474-480.

42. Gang, Y.P.; Cang, S.W.; Zhang, Y.H.; Li, Q.S. Self assembling Monolayers for Anti-moisture Absorption of Ammonium Nitrate. Chin. J. Appl. Chem. 2000, 17, 186-188.

43. Yin, P.-G.; Jin, G.-L.; Zhang, Y.-H.; Li, Q.-S. Structure Characterization of Self-Assembled Monolayer Film on the Surface of Ammonium Nitrate. J. Beijing Inst. Technol. 2000, 20, 643-646.

44. Yin, Y.-X.; Yang, R.-J. Modification of AN by using microencapsulation technology. Liaoning Chem. Ind. 2001, 30, 139. [CrossRef]

45. Xu, J.-M.; Liu, Z.-L.; Zhai, D.-D. Modification of inorganic salts by encapsulation method. Liaoning Chem. Ind. 2003, 32, 142.

46. Zhang, J. Study on Properties of the Coated AN with Polyvinyl Butyral. Chin. J. Explos. Propellants 2001, 24, 41-43.

47. Wei, Y.; Cai, B.H. Study on Surface Modification of Ammonium Nitrate. In Advanced Materials Research; Trans Tech Publications: Pfaffikon, Switzerland, 2011.

48. Zhang, J.; Yang, R.-J. Study on Surface Properties of Coated Ammonium Nitrate. Energetic Mater. 2004, $12,1-5$.

49. Zhang, J.Z.; Wang, X.Q.; Lin, D.-H. Study on Hygroscopicity of Ammonium Nitrate Particle Coated by Precipitation Polymerization of Styrene. Adv. Fine Petrochem. 2008, 12, 35-37.

50. Yu, Z.C.; Zhang, Y.J. Coating and modification of ammonium nitrate particles. Master's Thesis, Nanjing University of Science \& Technology, Nanjing, China, 2013.

(C) 2016 by the authors; licensee MDPI, Basel, Switzerland. This article is an open access article distributed under the terms and conditions of the Creative Commons Attribution (CC-BY) license (http:/ / creativecommons.org/licenses/by/4.0/). 